\title{
Morphological and Pathogenic Characterization of Sclerotium rolfsii, the Causal Agent of Southern Blight Disease on Common Bean in Uganda
}

\author{
Pamela Paparu, ${ }^{1, \dagger}$ Amos Acur, ${ }^{1}$ Fred Kato, ${ }^{2}$ Catherine Acam, ${ }^{2}$ Justine Nakibuule, ${ }^{1}$ Allan Nkuboye ${ }^{1}$, Stephen Musoke, ${ }^{2}$ \\ and Clare Mukankusi \\ ${ }^{1}$ National Crops Resources Research Institute, Namulonge, P.O. Box 7084 Kampala, Uganda \\ ${ }^{2}$ International Center for Tropical Agriculture (CIAT), P.O. Box 6247, Kampala, Uganda
}

\begin{abstract}
Over the last 5 years, Southern blight caused by Sclerotium rolfsii Sacc. has superseded root rots caused by pathogens such as Fusarium and Pythium spp. as a major constraint of common bean (Phaseolus vulgaris L.) production in Uganda. Although $S$. rolfsii is prevalent in all beangrowing regions of Uganda, there is a lack of information about its diversity and pathogenicity to guide the development of effective management strategies. In total, 348 S. rolfsii isolates were obtained from bean fields in seven agroecological zones of Uganda, with the following objectives: to characterize their morphology, based on mycelial growth rate, myce-

number of sclerotia produced on artificial media varied among agroecological zones but not within a zone. The five bean varieties tested were found to be susceptible to $S$. rolfsii, including varieties MLB49-89A and RWR719 that are resistant to Fusarium and Pythium root rots, respectively. Preemergence damping-off ranged between 0 and $100 \%$, and disease severity index ranged between 4.4 and $100 \%$. The widespread and high levels of $S$. rolfsii virulence on varieties of common bean indicate that management intervention is urgently required to help reduce losses incurred by Ugandan smallholder farmers.
\end{abstract} lium texture, and number of sclerotia; and to determine the pathogenicity of 75 selected isolates on five common bean varieties in artificially inoculated soils in a screenhouse. We found that mycelial growth rate and the
Keywords: dry bean, Phaseolus vulgaris, preemergence damping-off, Sclerotium root rot, Southern stem rot
The pathogen Sclerotium rolfsii Sacc. (teleomorph Arthelia rolfsii (Curzi) C. C. Tu \& Kimbr.) has a wide host range comprising more than 500 plant species and causes Southern blight disease, which results in significant crop yield losses worldwide. For example, it caused $80 \%$ yield losses in peanut (Arachis hypogaea L.) between 1988 and 1994 in the United States that led to economic losses of $\$ 36.8$ million (Franke et al. 1998). Southern blight, which is also termed sclerotium root rot or southern stem rot, was first identified on tomato (Solanum lycopersicum L.) in 1892 (Rolfs 1892) and is now known to occur across most crop types, particularly in warm regions (Aycock 1966; Domsch 1980; Farr et al. 1989). For example, the disease has been reported on common bean (Phaseolus vulgaris) in Uganda (Paparu et al. 2018), India (Mahadevakumar et al. 2015), and Italy (Garibaldi et al. 2013); maize (Zea mays) in Pakistan (Yasmin et al. 1984); soy bean (Glycine max) in Nigeria (Akem and Dashiell 1991); potato (S. tuberosum) in Italy (Garibaldi et al. 2006); okra (Abelmoschus esculentus) in Côte d'Ivoire (Koné et al. 2010); and sesame (Sesamum indicum L.) in Mexico (HernándezMorales et al. 2018).

${ }^{\dagger}$ Corresponding author: P. Paparu; pamela.paparu@gmail.com

Funding: Support was provided by the Biotechnology and Biological Sciences Research Council (BBSRC), the Department for International Development (DFID), and the Bill \& Melinda Gates Foundation (through a grant awarded to BBSRC; grant reference BB/J011436/1); and the United States Department of Agriculture National Institute of Food and Agriculture (USDA NIFA) (Prime Award Number 2012-39571-20296 and Subaward Number RC101980NaCRRI).

*The $\boldsymbol{e}$-Xtra logo stands for "electronic extra" and indicates that supplementary materials are published online.

The author(s) declare no conflict of interest.

Accepted for publication 3 March 2020

Copyright ( 2020 The Author(s). This is an open access article distributed under the CC BY 4.0 International license.
Key management strategies for Southern blight disease typically include the removal and destruction of infected plants which serve as sources of inoculum, the treatment of plants and seed with fungicides (e.g., Metalaxyl), and inclusion of nonhost plants in crop rotations. Other options include soil solarization (Chellemi 2002; Flores-Moctezuma et al. 2006), use of inorganic and organic soil fertility amendments (Bonanomi et al. 2007; Bulluck and Ristiano 2002; Flores-Moctezuma et al. 2006), and cultivation of resistant host plants (Woodward et al. 2008).

Symptoms of Southern blight include gray and water-soaked lesions on the stem above the soil line; plant surface mycelia and sclerotia; seed rot or preemergence damping-off; seedling root rot; and stem, fruit, tuber, and pod rots (Mullen 2001). Sclerotium rolfsii produces abundant hyphae and sclerotia (Mullen 2001) as asexual resting structures that facilitate pathogen survival in the absence of the host (Adams and Ayers 1979).

Morphological and phenotypic diversity of pathogens may be related to variation in virulence that is important in the selection of pathogen isolates used for the evaluation of disease resistance in crop breeding programs. Variability among $S$. rolfsii isolates and related species such as $S$. sclerotiorum that infect different crops has been investigated in studies relating to sclerotia morphology traits and mycelial growth rates (Lehner et al. 2014; Narayan et al. 2017; Vleugels et al. 2013), pathogenicity in susceptible host plants, and genetics using molecular markers (Jebaraj et al. 2017; Narayan et al. 2017).

Previous work in Uganda showed that common bean yield losses caused by Southern blight in artificially inoculated trials ranged between 4 and $76 \%$ over two study seasons (P. Paparu, unpublished data). However, despite the threat of this disease to common bean production (Paparu et al. 2018), knowledge of the morphology and pathogenicity of $S$. rolfsii isolates from common-bean-growing regions in Uganda is lacking. Thus, the objectives of this study were to, first, determine regional differences in $S$. rolfsii growth rate and sclerotia formation and, second, assess the variation in the pathogenicity of selected isolates on common bean.

\section{Materials and Methods}

Sample collection. For isolation of $S$. rolfsii, wilting plant samples were collected from seven agroecological zones in Uganda: the 
Eastern highlands, Lake Victoria basin and Mbale farmlands, Northern mixed farming zone, Southwestern highlands, Teso farming zone, Western mixed farming zone, and West Nile mixed farming zone (Fig. 1). Samples were collected over three seasons (March to June and August to November 2013 and March to June 2014) during surveys to determine the prevalence and incidence of root rots of common bean in Uganda (Paparu et al. 2018). The mean annual temperature and rainfall for the agroecological zones (Wortmann and Eledu 1999) and elevation ranges obtained using a GPS during sample collection are detailed in Table 1 .

In all, five wilting plants that showed characteristic symptoms of Southern blight disease were collected along a Z-transect in each surveyed field; plants were placed in a paper bag for each field and brought to the pathology laboratories at the National Crops Resources Research Institute and the International Center for Tropical Agriculture-Uganda laboratory at the National Agricultural Research Laboratories in Kawanda, Uganda, for isolation of S. rolfsii. In total, 2,000 plants were collected, including five peanut plants.

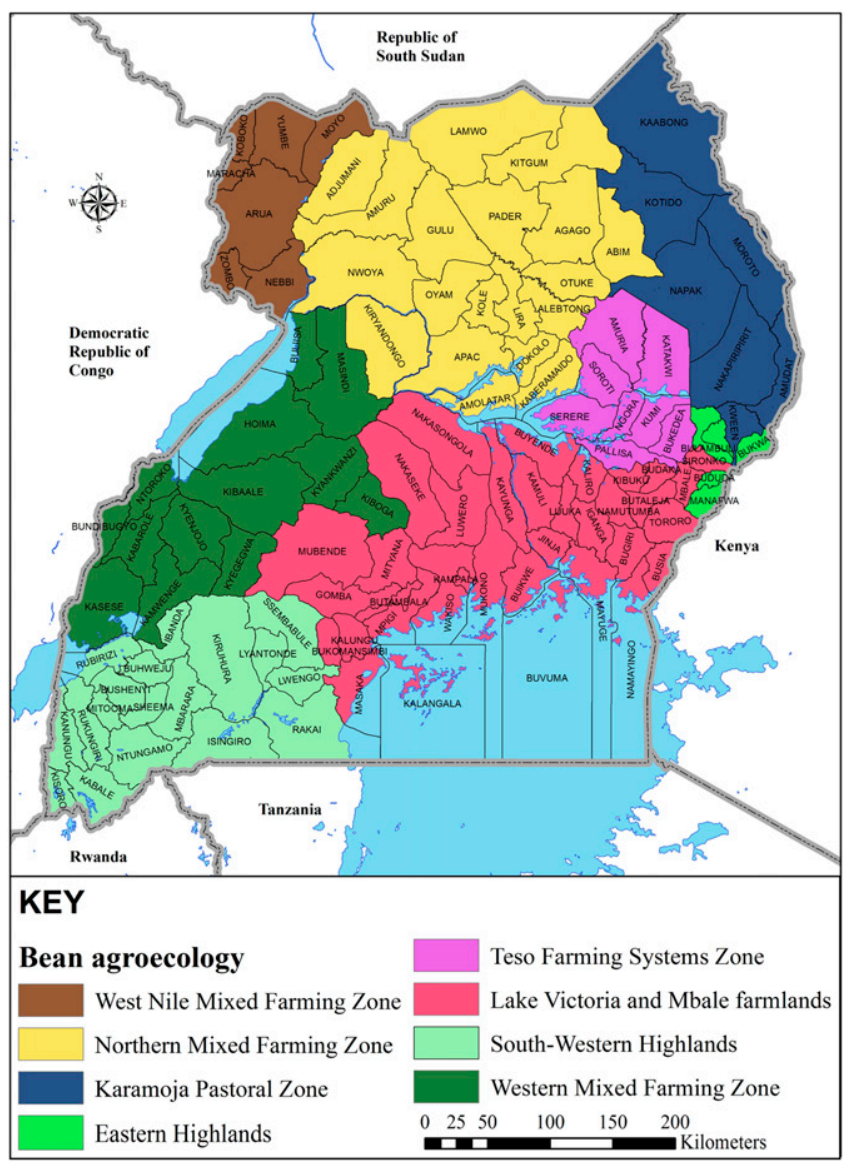

Fig. 1. Agroecological zones in Uganda from which wilting plants were collected for isolation of Sclerotium rolfsii.
Isolation of $S$. rolfsii and culture maintenance. Plant roots were washed under running tap water and cut into 5-mm sections. Five root sections per sample were surface sterilized by dipping in 5\% sodium hypochlorite for $1 \mathrm{~min}$ and then in $70 \%$ ethanol for a further minute. They were then rinsed thrice in sterile distilled water, blotted dry on sterile tissue paper, and plated on potato dextrose agar (PDA) (distilled water at $39 \mathrm{~g} /$ liter) (Sigma-Aldrich, Steinheim, Germany) in 90-mm Petri dishes, supplemented with rifamycin antibiotic (SigmaAldrich Chemie GmbH, Steinheim, Germany) at $0.03 \mathrm{~g} /$ liter.

The plates were incubated on a laboratory bench at approximately $25^{\circ} \mathrm{C}$ for a photoperiod of approximately $12 \mathrm{~h}$ (light) and $12 \mathrm{~h}$ (dark) for 7 days. All emerging fungal colonies identified as $S$. rolfsii using cultural characteristics described by Prasad (2012) were subcultured on PDA for 7 days, after which pure isolate cultures were prepared using single-sclerotia isolation and hyphal tipping. For hyphal tipping, 3-mm-diameter plugs of PDA containing fully grown mycelia were excised from the initial plate and placed on water agar $(13.2 \mathrm{~g}$ of agar in 1 liter of water) for $24 \mathrm{~h}$ in darkness, at approximately $25^{\circ} \mathrm{C}$. Hyphal tipping was done using a sterile needle under a stereomicroscope (Leica, Wild M3B; Leica Systems, Germany), and cultures were grown on PDA with rifamycin at $0.03 \mathrm{~g} /$ liter. The resulting pure cultures were grown on sterile filter paper (autoclaved twice for $1 \mathrm{~h}$ at $121^{\circ} \mathrm{C}$ and $15 \mathrm{psi}$ ) for long-term storage according to the method of Fong et al. (2000), with modifications. Fifteen pieces of triangularshaped sterile filter papers cut to a size to fit in a 1.5-ml Eppendorf tube were placed in a sterile Petri dish and overlaid with a thin layer of water agar. Then, PDA plugs ( $3 \mathrm{~mm}$ in diameter) containing fully grown mycelia were excised from pure cultures, placed on the filter papers (maximum of three plugs per Petri dish), and incubated for 3 to 4 weeks in darkness at approximately $25^{\circ} \mathrm{C}$. During the incubation period, mycelia grew and dried on the filter paper. Under the aseptic conditions of a laminar flow cabinet, the dried filter papers for each isolate were placed in 1.5-ml Eppendorf tubes and kept at $-20^{\circ} \mathrm{C}$ for long-term storage.

Morphological characterization of $S$. rolfsii isolates. In total, $348 \mathrm{~S}$. rolfsii isolates obtained from the seven agroecological zones were assessed for colony growth rate, color and texture of mycelia, and number of sclerotia produced. Three replicates of 3-mmdiameter agar disks from 3-day-old cultures were placed at the center of three separate 90-mm-diameter Petri dishes (replicates 1, 2, and 3) that contained freshly prepared PDA amended with rifamycin at 0.03 $\mathrm{g} /$ liter and incubated at $25^{\circ} \mathrm{C}$. From the second day of incubation, colony diameter was measured using a ruler along two perpendicular lines drawn on the bottom of each Petri dish. Measurements were completed between 5 and 7 days, when most of the cultures had grown beyond the Petri dish base. Colony texture was examined with the naked eye and recorded at 7 days. The number and color of sclerotia were recorded for 14 to 28 days after inoculation, using the descriptions by Mullen (2001). We assigned the 348 isolates to morphological groups according to mycelial growth rate and number of sclerotia produced (Table 2).

Pathogenicity of $S$. rolfsii isolates on common bean. We selected $75 \mathrm{~S}$. rolfsii isolates based on morphological grouping and agroecological zone for inoculation on five varieties of common bean: MLB49-89A (Fusarium root rot resistant) (Ongom et al. 2012), RWR719 (Pythium root rot resistant variety) (Otsyula et al.

Table 1. Mean annual temperature and rainfall, and altitude range in the seven contrasting agroecological zones in Uganda where Sclerotium rolfsii isolates were collected

\begin{tabular}{lccr}
\hline Agroecological zone & Temperature $\left({ }^{\circ} \mathbf{C}\right)$ & Rainfall $(\mathbf{m m})$ & Altitude $(\mathbf{m a s}))^{\mathbf{z}}$ \\
\hline Eastern highlands & 20 & 1,337 & $1,500-2,200$ \\
Lake Victoria basin and Mbale farmlands & 22 & 1,211 & $1,040-1,433$ \\
Northern mixed farming & 24 & 1,258 & $942-1,182$ \\
Southwestern highlands & 16 & 1,177 & $1,247-2,313$ \\
Teso farming & 23 & 795 & $1,072-1,130$ \\
Western mixed farming & 20 & 1,140 & $1,052-1,501$ \\
West Nile mixed farming & 23 & 1,304 & $918-1,454$ \\
\hline
\end{tabular}

${ }^{\mathrm{z}}$ Altitude in meters above sea level (masl). 
2003), ALB123 (hybrid of Pythium coccineus and P. vulgaris), NABE15 (commercially available), and K132 (susceptible; CAL96). Pathogenicity tests were conducted using a protocol adapted for Fusarium solani (Mukankusi et al. 2011). Inoculum was prepared using $50 \mathrm{~g}$ of moistened millet grain in conical flasks that were autoclaved twice on two consecutive days and allowed to cool under sterile conditions in a laminar flow cabinet. Then, the grains were inoculated with four to five agar plugs, $5 \mathrm{~mm}$ in diameter, from actively growing cultures and the flasks were plugged with sterile cotton wool, covered with sterile aluminum foil, and incubated on a laboratory bench for 3 to 4 weeks; the grains were mixed weekly under sterile conditions to allow for even growth of the fungus. When the grains had been fully colonized by the fungus, three replicates of $10 \mathrm{~g}$ of inoculum for each isolate was thoroughly mixed with approximately $20 \mathrm{~kg}$ of steam-sterilized soil (2:1 ratio of loam/sand) in a 70by-35-by-10-cm wooden tray in which we sowed 16 seeds of each variety along two rows. We used a randomized complete block design, with the replicates as blocks. Isolates were randomized within the replicates and rows of each variety were completely randomized within each tray. Seed from the five varieties were sown in noninoculated soils as controls. The 75 isolates were screened in six separate experiments due to the limited number of trays and limited screenhouse space.

At 14 days after inoculation, we recorded germination (seed emergence) and incidence of Southern blight disease. Nonemerged seed were removed from the soil to assess the presence of preemergence damping-off caused by $S$. rolfsii. Positive preemergence damping-off was recorded for seed that were visibly rotten and those that had germinated and failed to emerge above the soil surface and were covered with mycelia or sclerotia. Southern blight severity was assessed at 28 days after inoculation using a modified scale reported by Le et al. (2012) (Table 3; Fig. 2).

Data analysis. The SAS statistical software (version 9.1; SAS Institute, Cary, NC, U.S.A.) was used for data analysis. Differences in isolate growth rate and number of sclerotia across agroecological zones were analyzed using Tukey's Studentized range test. Southern blight disease severity index (DSI) by variety (data pooled across the six experiments) was analyzed using the PROC GLM procedure in SAS.

The DSI was calculated after Chiang et al. (2017): DSI $(\%)=$ $[\Sigma$ (class frequency $\times$ score of rating class)/(total number of observations $\times$ maximal disease index) $] \times 100$.

In order to determine the effect of $S$. rolfsii isolates on seed germination, seed germination percentage, preemergence damping-off, and DSI values were arcsine square root transformed prior to analysis to ensure homogeneity of variance.

Associations between growth rate and number of sclerotia produced and between growth rate-number of sclerotia and Southern

Table 2. Definition of Sclerotium rolfsii morphological groups based on mycelial and sclerotial characteristics

\begin{tabular}{|c|c|c|}
\hline Morphological group & Mycelial growth rate & $\begin{array}{c}\text { Sclerotia } \\
\text { number/ } \\
\text { Petri dish }^{\mathrm{z}}\end{array}$ \\
\hline 1 & High & High \\
\hline 2 & High & Medium \\
\hline 3 & High & Low \\
\hline 4 & Medium & High \\
\hline 5 & Medium & Medium \\
\hline 6 & Medium & Low \\
\hline 7 & Low & High \\
\hline 8 & Low & Medium \\
\hline 9 & Low & Low \\
\hline \multicolumn{3}{|c|}{$\begin{array}{l}\text { y Mycelia growth was recorded daily until day seven after inoculation, by } \\
\text { which time most of the isolates had covered the bottom of the Petri dish. } \\
\text { High }=\text { slope } \geq 25 \text {, Medium }=\text { slope } 20 \text { to } 24 \text {, and Low }=\text { slope } \leq 19 \text {. } \\
\mathrm{z} \text { Number of sclerotia produced per isolate on a single Petri dish was counted } \\
28 \text { days after inoculation. High }=\geq 200 \text {, Medium }=50 \text { to } 199 \text {, and Low }= \\
\leq 49 \text {. }\end{array}$} \\
\hline
\end{tabular}

blight disease severity were tested using Spearman's rank correlation in SAS. For all analyses, significance was evaluated at $P \leq 0.05$.

\section{Results}

Growth and sclerotia characteristics of $S$. rolfsii isolates. Using the convention published by Mahato and Biswas (2017), we characterized the morphology of 348 isolates of $S$. rolfsii based on growth, colony texture and color, and number of sclerotia formed 28 days after culture initiation. All isolates formed white cultures with fluffy, fibrous, or compact mycelia (Fig. 3)-fluffy mycelia were most common $(84.7 \%)$, followed by thin fibrous mycelia $(9.2 \%)$ and compact mycelia $(6.1 \%)$. There were differences in growth rate among the agroecological zones $(P=0.0001)$ (Table 4).

Isolates formed small round (Fig. 3A, B, and C) or large irregularshaped (Fig. 3D) sclerotia that were either light or dark brown. Of the 348 isolates, $69.6 \%$ formed light-brown sclerotia, while $30.4 \%$ had dark-brown sclerotia, and the number of sclerotia varied among the agroecological zones (Table 4).

Growth rate varied between the agroecological zones, with the highest observed for isolates from Teso farming and the lowest from the Eastern highland (Table 4). Similarly, growth rate for isolates from the same agroecological zone was different $(P<0.0001)$ and this was true for all seven zones studied. Growth rates ranged from 11.6 to $25.7(n=3), 10.4$ to $26.6(n=150), 10.7$ to $26.7(n=36)$, 11.4 to $16.7(n=25), 21.6$ to $27.3(n=80), 19.4$ to $29.2(n=43)$, and 20.4 to $27.5(n=11)$ for Eastern highlands, Lake Victoria basin and Mbale farmlands, Northern mixed farming, Southwestern highlands, West Nile farming, Western mixed farming, and Teso farming, respectively. Growth rate was negatively associated with number of sclerotia produced $(r=-0.33, P<0.0001)$.

Morphological grouping of $S$. rolfsii isolates. We grouped the 348 S. rolfsii isolates into nine morphological groups (Table 2) based on growth rate and number of sclerotia produced. We found that no single agroecological zone comprised all the groups. Morphological groups 3 and 6 were the most abundant $(28.7$ and $27.0 \%$, respectively) and mostly derived from the Lake Victoria basin and Mbale farmlands and Western mixed farming agroecological zones (Table 5). In all, 11 isolates (3.2\%) had low growth rates but produced high numbers of sclerotia (morphological group 7) and, of these, 6 were derived from the Southwestern highlands and 5 from the Western mixed farming agroecological zones. Morphological group 8 was represented by a single isolate collected from the Southwestern highlands.

Pathogenicity of $S$. rolfsii isolates. We selected $75 \mathrm{~S}$. rolfsii isolates representing the nine morphological groups to evaluate their pathogenicity on five varieties of common bean. All tested isolates were pathogenic on common bean, including one (HOI356-Peanut) that was isolated from a peanut volunteer in a bean field. The effect of the isolates on seed germination, preemergence damping-off, and

Table 3. Definition of Southern blight disease severity scores based on visible symptoms found on common bean plants grown in soils infested with Sclerotium rolfsii

\begin{tabular}{lc}
$\begin{array}{l}\text { Severity } \\
\text { score }\end{array}$ & \multicolumn{1}{c}{ Description } \\
\hline 1 & No symptoms; plant healthy \\
& $\begin{array}{c}\text { Gray water-soaked lesions present on stem above } \\
\text { soil, but no visible fungal outgrowth } \\
\text { Visible fungal outgrowth on stem base, } \\
\text { characterized by silky-white mycelia or sclerotia } \\
\text { that gradually darken }\end{array}$ \\
3 & $\begin{array}{l}\text { Partial wilting, where younger leaves begin to wilt } \\
\text { and stems begin to shrivel } \\
\text { Complete wilting, desiccation and browning of } \\
\text { leaves and stem; plant collapse and death (rot) }\end{array}$ \\
5 & Preemergence damping-off; complete seed rot, \\
& with no sign of germination, or evidence of \\
& germination hampered by fungal colonization \\
\hline
\end{tabular}


Southern blight disease severity differed (Table 6; Supplementary Table S1).

Preemergence damping-off ranged from 0\% (by isolate KYG33) to $100 \%$ (by isolate LWR100); isolate KYG33 did not affect seed germination of any of the five common bean varieties, whereas isolate LWR100 completely inhibited seed germination in all varieties (Supplementary Table S1). These two fungal isolates were obtained from the Lake Victoria basin and Mbale farmlands agroecological zones. Disease severity ranged between 4.4 and 100\%; the lowest disease severity was caused by isolate SRT110 from the Teso farming agroecological zone.

Susceptibility of common bean varieties tested. There were differences in preemergence damping-off, seed germination, and Southern blight disease severity among the varieties following growth in soils infested with $S$. rolfsii (Table 7). Seed germination rates were greater and DSI was lower in MLB49-89A and RWR719 (resistant to Fusarium and Pythium root rots, respectively) and ALB123 (hybrid) than in the susceptible K132 and commercial NABE15 $(P<$ $0.0001)$. Preemergence damping-off was greater in K132 and NABE 15 than in MLB49-89A and RWR719 $(P<0.0001)$. There was a variation in disease severity caused by 10 of the 75 isolates tested on five common bean varieties $(P \leq 0.05)$ (Fig. 4). Similarly, preemergence damping-off caused by 22 isolates varied among the five varieties $(P \leq 0.05)$ (Fig. 5).

We found weak but positive correlations between the number of sclerotia produced by an isolate and its ability to cause preemergence damping-off ( $r=0.27, P=0.018)$, and between sclerotia number and Southern blight DSI $(r=0.28, P=0.015)$. There was no correlation between mycelial growth rate and Southern blight disease severity.

\section{Discussion}

Uganda is a major hub for common bean production in subSaharan Africa and diseases affecting this crop are of concern. Southern blight caused by $S$. rolfsii is an emergent disease of common bean in Uganda and is currently the most important soilborne disease of common bean in the country (Paparu et al. 2018). Therefore, it is essential to determine its distribution and virulence in order to facilitate development of sustainable management practices. Our study is the first to report on the morphology and pathogenicity of Ugandan $S$. rolfsii isolates on common bean.

We found variation in colony morphology, mycelial growth rates, number of sclerotia produced, and morphological groups among $S$. rolfsii isolates from the seven Ugandan agroecological zones. For example, we found 3 isolates from the Eastern highland zone and each belonged to a different morphological group, and the 80 isolates obtained from the Western mixed farming agroecological zone

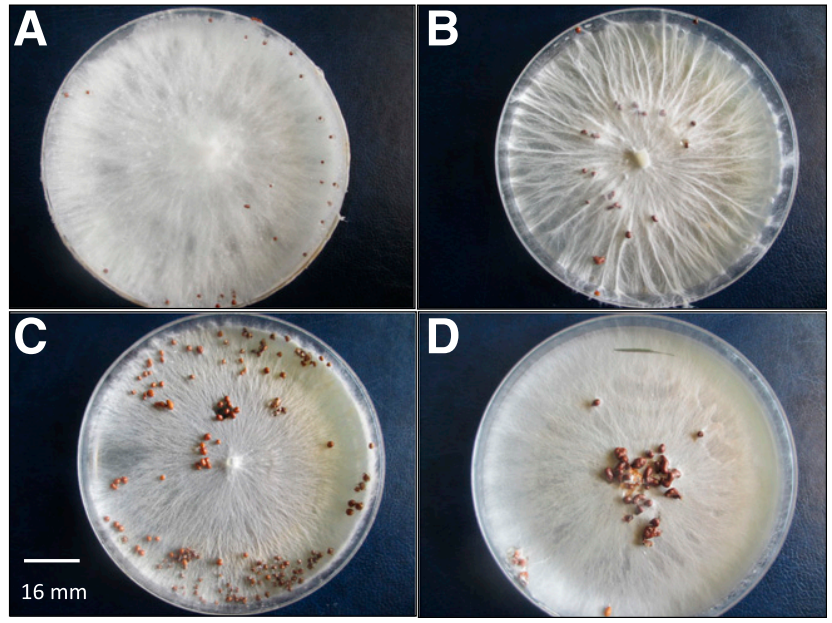

Fig. 3. Phenotypic characteristics of selected Sclerotium rolfsii isolates from Ugandan common bean agroecological zones 28 days after inoculation on potato dextrose agar. A, Fluffy mycelia; B, thin fibrous mycelia; C, thin compact mycelia with small-sized sclerotia; and $\mathbf{D}$, thin compact mycelia with large irregular-shaped sclerotia.

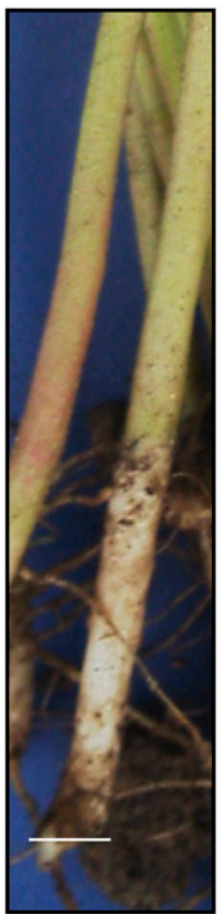

1

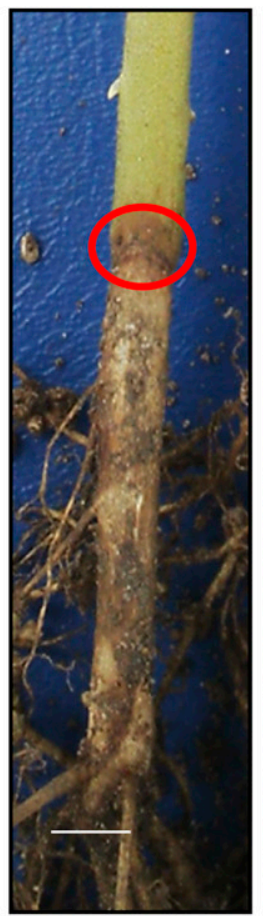

2
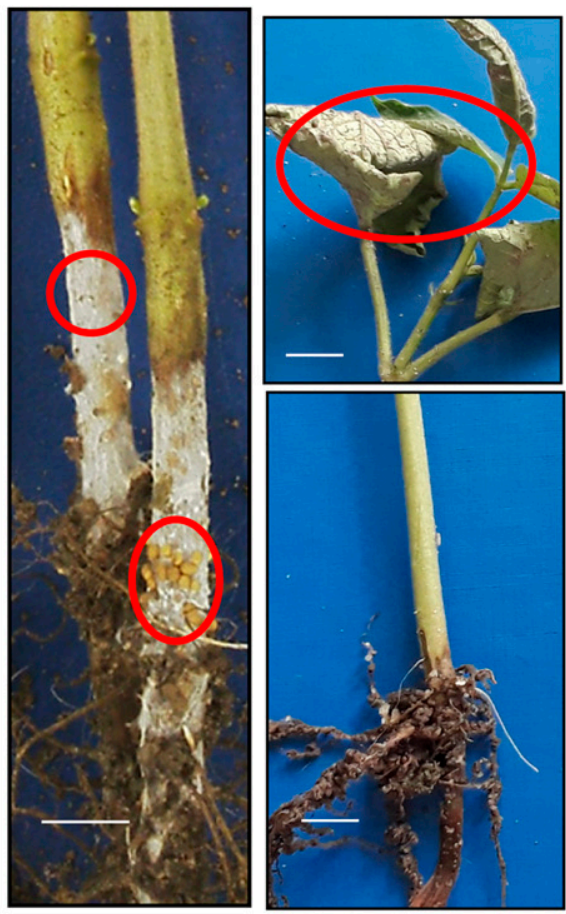

4

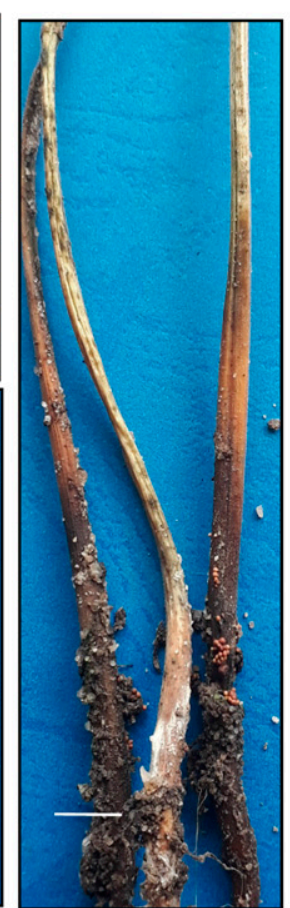

5

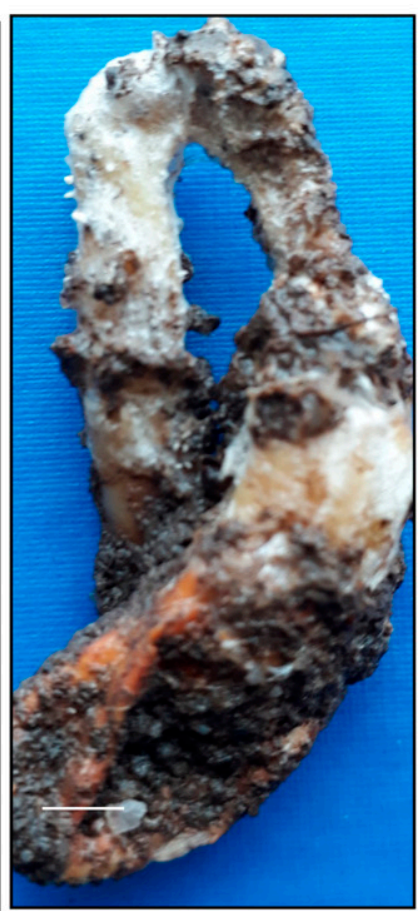

6

Fig. 2. Southern blight disease severity index scale (1 to 6$): 1=$ no disease symptoms, $2=$ gray water-soaked lesions on the stem above the soil with no visible fungal outgrowth, $3=$ gray water-soaked lesions on the stem above the soil with visible fungal outgrowths such as mycelia and sclerotia, $4=$ partial wilting, $5=$ complete wilting and necrosis, and $6=$ preemergence damping-off. Scale bar $=5 \mathrm{~mm}$. 
belonged to eight distinct groups. In related studies, $S$. rolfsii characterization using mycelial compatibility groups (MCGs) found great diversity within isolates from limited geographical areas. For example, Harlton et al. (1995) identified seven MCGs for 38 S. rolfsii isolates from the United States, and it has been suggested that genetically related isolates often occupy the same MCG (Le et al. 2012; Xie et al. 2014).

In our study, we found that mycelial growth rate varied among the agroecological zones, with isolates from the cool Eastern highland zone showing slower growth than those from the other six zones. We speculate that these isolates have adapted to lower temperatures; therefore, culturing them at $25^{\circ} \mathrm{C}$ in our study may not have been optimal. This observation requires validation, because very few isolates were screened from this region. We found no difference in mycelial growth rates among isolates within an agroecological zone; this may be because, generally, variations in temperature and humidity within a single zone are minimal. The white fluffy or compact type of $S$. rolfsii mycelia observed in this study have been reported previously (Le et al. 2012, Xie et al. 2014). Isolates from peanut in Vietnam had silky-white mycelia (Le et al. 2012), while those from southern United States had thin, compact white mycelia, and those from other diverse crops had fluffy white mycelia (Xie et al. 2014), in contrast to isolates from sweetpotato (Ipomoea batatas) in Korea that were characterized by white to pale-brown mycelia (Narayan et al. 2017).

There tended to be no difference in the number of sclerotia produced among isolates, possibly due to high within-isolate variation. For example, isolate KAP415 formed 388, 338, and 0 sclerotia and isolate SIR160-1 produced 43, 50, and 1 sclerotia in replicates 1, 2 , and 3, respectively. Although sclerotia formation was not uniform among our isolates, 4 of the 348 isolates consistently failed to produce any sclerotia. Differences in sclerotia number and size among isolates of $S$. rolfsii have been reported (Le et al. 2012; Narayan et al. 2017; Xie et al. 2014). In a related study, Lehner et al. (2014)

Table 4. Differences in mean growth rate (millimeters per day) and number of sclerotia for Sclerotium rolfsii isolates from seven agroecological zones in Uganda ${ }^{z}$

\begin{tabular}{lccc}
\hline Agroecological zone & Mean growth rate $( \pm$ SE) & Mean number of sclerotia $( \pm$ SE) & Number of isolates \\
\hline Eastern highlands & $20.7 \pm 4.37 \mathrm{~b}$ & $225.7 \pm 113.9 \mathrm{a}$ & 3 \\
Lake Victoria basin and Mbale farmlands & $24.5 \pm 0.18 \mathrm{a}$ & $48.6 \pm 8.23 \mathrm{~b}$ & $79.7 \pm 25.0 \mathrm{~b}$ \\
Northern mixed farming & $22.8 \pm 0.6 \mathrm{ab}$ & $165.3 \pm 39.4 \mathrm{ab}$ & 36 \\
Southwestern highlands & $22.4 \pm 1.32 \mathrm{ab}$ & $11.3 \pm 7.36 \mathrm{~b}$ & 25 \\
Teso farming & $25.2 \pm 0.67 \mathrm{a}$ & $121.0 \pm 15.9 \mathrm{ab}$ & 11 \\
Western mixed farming & $23.3 \pm 0.34 \mathrm{ab}$ & $119.3 \pm 7.38 \mathrm{ab}$ & 80 \\
West Nile mixed farming & $24.1 \pm 0.25 \mathrm{a}$ & 43 \\
\hline
\end{tabular}

${ }^{\mathrm{z}}$ Different lowercase letters within a column indicate differences among agroecological zones at $P \leq 0.05$ (Tukey's Studentized range test). SE $=$ standard error.

Table 5. Morphological grouping of Sclerotium rolfsii isolates from seven agroecological zones in Uganda

\begin{tabular}{|c|c|c|c|c|c|c|c|c|c|}
\hline \multirow[b]{2}{*}{ Agroecological zone } & \multicolumn{9}{|c|}{ Isolates per morphological group ${ }^{z}$} \\
\hline & 1 & 2 & 3 & 4 & 5 & 6 & 7 & 8 & 9 \\
\hline Eastern highlands & 1 & 0 & 0 & 1 & 0 & 0 & 0 & 0 & 1 \\
\hline Lake Victoria basin and Mbale farmlands & 4 & 13 & 63 & 8 & 7 & 51 & 0 & 0 & 2 \\
\hline Northern mixed farming & 0 & 1 & 9 & 3 & 10 & 9 & 0 & 0 & 4 \\
\hline Southwestern highlands & 0 & 8 & 8 & 0 & 1 & 0 & 6 & 1 & 1 \\
\hline Teso farming & 1 & 5 & 2 & 0 & 0 & 5 & 0 & 0 & 0 \\
\hline Western mixed farming & 6 & 8 & 14 & 10 & 11 & 23 & 5 & 0 & 3 \\
\hline West Nile mixed farming & 4 & 10 & 4 & 4 & 15 & 6 & 0 & 0 & 0 \\
\hline Total & 16 & 45 & 100 & 26 & 44 & 94 & 11 & 1 & 11 \\
\hline Proportion (\%) & 4.6 & 12.9 & 28.7 & 7.5 & 12.6 & 27.0 & 3.2 & 0.3 & 3.2 \\
\hline
\end{tabular}

${ }^{\mathrm{z}}$ Morphological group $1=$ high growth rate and high number of sclerotia, $2=$ high growth rate and medium number of sclerotia, $3=$ high growth rate and low number of sclerotia, $4=$ medium growth rate and high number of sclerotia, $5=$ medium growth rate and medium number of sclerotia, $6=$ medium growth rate and low number of sclerotia, $7=$ low growth rate and high number of sclerotia, $8=$ low growth rate and medium number of sclerotia, and $9=$ low growth rate and low number of sclerotia, where high growth rate $=>25 \mathrm{~mm}$ per day, medium $=20$ to $24 \mathrm{~mm}$ per day, and low $=\leq 19 \mathrm{~mm}$ per day; and high sclerotia number $=>200$ per Petri dish, medium $=50$ to 99 per Petri dish, and low $=\leq 49$ per Petri dish.

Table 6. Effects of common bean variety $(N=5)$ and Sclerotium rolfsii isolate $(N=75)$ on indicators of Southern blight disease development

\begin{tabular}{|c|c|c|c|c|c|c|}
\hline \multirow[b]{2}{*}{ Factor } & \multicolumn{2}{|c|}{ Preemergence damping-off } & \multicolumn{2}{|c|}{ Germination } & \multicolumn{2}{|c|}{ Disease severity index } \\
\hline & $F$ value & $P$ value & $F$ value & $P$ value & $F$ value & $\overline{P \text { value }}$ \\
\hline Variety & 26.78 & $<0.0001$ & 26.85 & $<0.0001$ & 4.64 & 0.0010 \\
\hline Isolate & 157.32 & $<0.0001$ & 156.60 & $<0.0001$ & 24.48 & $<0.0001$ \\
\hline Variety $\times$ isolate & 3.27 & $<0.0001$ & 3.24 & $<0.0001$ & 0.55 & 1.0000 \\
\hline
\end{tabular}

Table 7. Differences in mean percentage ( \pm standard error) of Southern blight disease parameters among five common bean varieties after sowing in artificially inoculated soils in the screenhouse ${ }^{\mathrm{Z}}$

\begin{tabular}{lccr}
\hline Variety & Preemergence damping-off & Germination & Disease severity index \\
\hline ALB123 & $34.9 \pm 0.85 \mathrm{ab}$ & $62.8 \pm 0.89 \mathrm{bc}$ & $48.6 \pm 2.47 \mathrm{~b}$ \\
K132 & $37.7 \pm 0.86 \mathrm{a}$ & $59.8 \pm 0.90 \mathrm{~cd}$ & $52.4 \pm 2.64 \mathrm{a}$ \\
MLB49-89A & $31.6 \pm 0.83 \mathrm{c}$ & $66.4 \pm 0.87 \mathrm{a}$ & $46.9 \pm 2.54 \mathrm{~b}$ \\
NABE15 & $38.1 \pm 0.86 \mathrm{a}$ & $59.2 \pm 0.91 \mathrm{~d}$ & $53.6 \pm 2.58 \mathrm{a}$ \\
RWR719 & $31.7 \pm 0.83 \mathrm{bc}$ & $66.1 \pm 0.87 \mathrm{ab}$ & $47.8 \pm 2.52 \mathrm{~b}$ \\
\hline
\end{tabular}

${ }^{\mathrm{z}}$ Different lowercase letters within a column indicate differences among varieties at $P \leq 0.05$ (Tukey's Studentized range test). 
observed variation in the number of sclerotia produced by isolates in two different experiments using a related fungal species ( $S$. sclerotiorum). Although Lehner et al. (2014) and Li et al. (2008) found no correlation between mycelial growth rate and the number of sclerotia produced by isolates of $S$. sclerotiorum, we found that these factors were negatively correlated for isolates of $S$. rolfsii.

This study is the first to report the importance of preemergence damping-off caused by $S$. rolfsii in common bean. In total, 8 of the 75 isolates caused between 90 and $100 \%$ preemergence dampingoff in seed planted in infested soils; other symptoms exhibited by seedlings included blackening and water-soaked lesions on the stem tissue above the soil, wilting, formation of sclerotia at the base of the plant, and necrosis. Similar observations were made by Blum and Rodriquez-Kabana (2004) and Kator et al. (2015). High levels of preemergence damping-off and wilting that lead to plant death reduce standing plant density at harvest, thus increasing yield losses (Fery and Dukes 2002; Franke et al. 1998).

Virulence of $S$. rolfsii isolates on the five test varieties varied. Preemergence damping-off and disease severity caused by all isolates (combined effect) was greater in the susceptible K132 variety and the commercially available NABE15. S. rolfsii isolates were equally virulent on varieties MLB49-89A (Fusarium root rot resistant) and RWR719 (Pythium root rot resistant), causing preemergence damping-off and Southern blight disease (Table 7). It is interesting to know that resistance to $S$. rolfsii has been reported in a range of crops, including cowpea, sweet potato, pepper, tomato (Dukes et al. 1983), and alfalfa (Pratt and Rowe 2002). Xie et al. (2014) reported variation in disease symptoms on pepper and tomato varieties inoculated with $S$. rolfsii. Kator et al. (2015) found differences in the virulence of a single isolate of $S$. rolfsii on three varieties of tomato in Nigeria, where damping-off at 3 weeks in variety Hoozua was $66.6 \%$ and in varieties Shase and UTC was $83.3 \%$.

In our study, the virulence of 10 isolates varied among the five tested bean varieties, ranging from high (DSI $\geq 50 \%$ ) to low (DSI $\leq 50 \%$ ) (Fig. 4). Similarly, preemergence damping-off among the five varieties varied for $22 \mathrm{~S}$. rolfsii isolates. Several studies on the pathogenicity of $S$. rolfsii have similarly showed isolate differences in virulence. For example, Xie et al. (2014) observed differences in virulence among $S$. rolfsii isolates inoculated on pepper and tomato, and Mahato and Biswas (2017) found variation in the virulence of 10 $S$. rolfsii isolates on a single variety of tomato. In a related study, Jebaraj et al. (2017) showed differences in virulence of $S$. rolfsii isolates from peanut obtained from different regions of India.

We found no correlation between mycelial growth rate and disease severity, in contrast to results of Punja et al. (1985), who observed that $S$. rolfsii isolates with high growth rates also had high virulence (characterized by symptoms of water soaking, root colonization, and seedling infection). Mullen (2001) reported that the production of large quantities of oxalic acid by fast-growing isolates causes tissue degradation during the $S$. rolfsii infection process. Similarly, contrasting effects of the closely related $S$. sclerotiorum have been reported; for example, Vleugels et al. (2013) found a positive correlation between mycelial growth rate and isolate aggressiveness but Lehner et al. (2016) reported no such association. These contradictory findings indicate that mycelial growth rate may not be a reliable marker for aggressiveness of $S$. rolfsii isolates.

Unlike our results for mycelial growth rate, we noted weak positive correlations between sclerotia number and preemergence damping-off and between sclerotia number and Southern blight disease severity. Vleugels et al. (2013) suggested that a negative correlation between sclerotia number and isolate aggressiveness in $S$. sclerotiorum may be due to the production of sclerotia at the expense of enzyme production for host tissue invasion. However, we did not find published reports on the association between number of sclerotia produced and aggressiveness of $S$. rolfsii isolates. In our study, some isolates exhibited a high degree of aggressiveness and produced high numbers of sclerotia on PDA media. We hypothesize that this was due to the ability of these isolates to produce large numbers of sclerotia in the millet inoculum which, in turn, increased the chances of host colonization. Sclerotia are known to play an important role in disease cycles by germinating vegetatively for local colonization (Bolton et al. 2006) and acting as inoculum; they are the primary

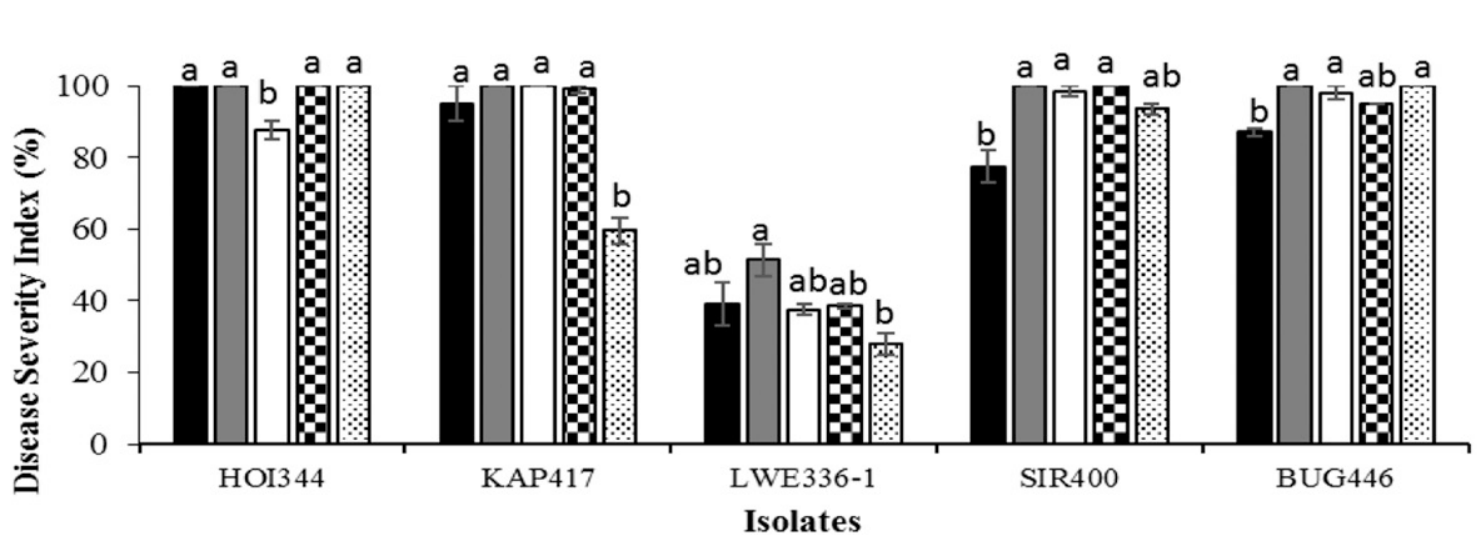

-ALB123

口K132

口MLB49-89A

๑NABE15

口RWR719

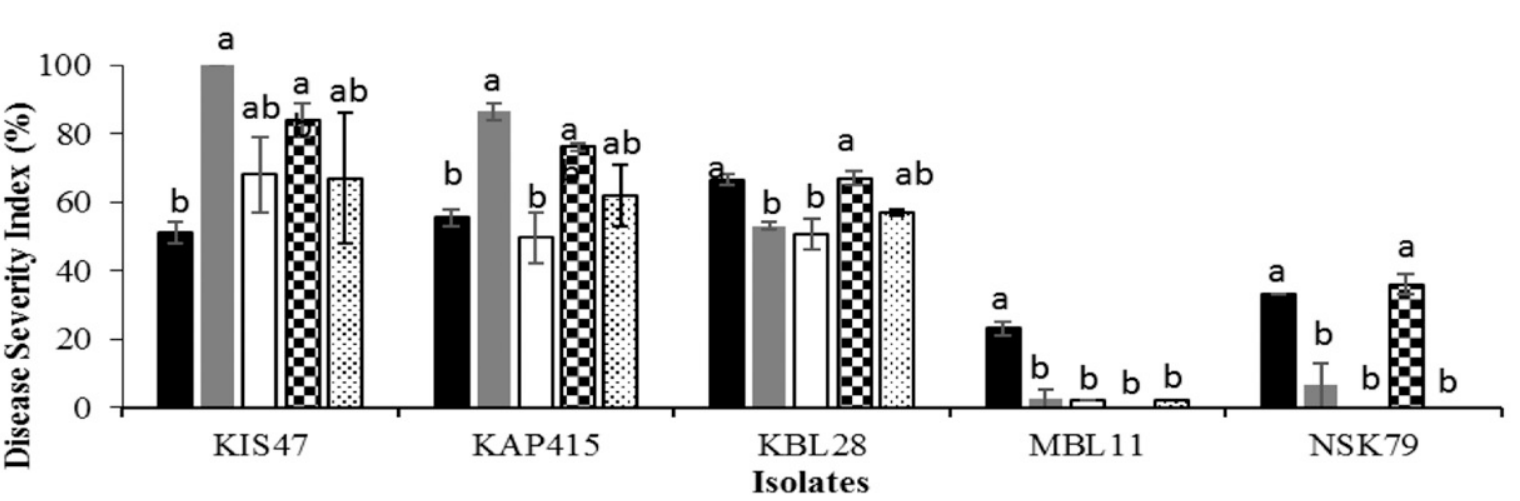

-ALB123

- 132

口MLB49-89A

QNABE15

QRWR719

Fig. 4. Southern blight disease severity caused by selected Sclerotium rolfsii isolates that varied in their effect on common bean test varieties ALB123, K132, MLB49-89A, NABE15, and RWR719. For each isolate, different letters indicate differences in disease severity index at $P \leq 0.05$ (Tukey's Studentized range test). 


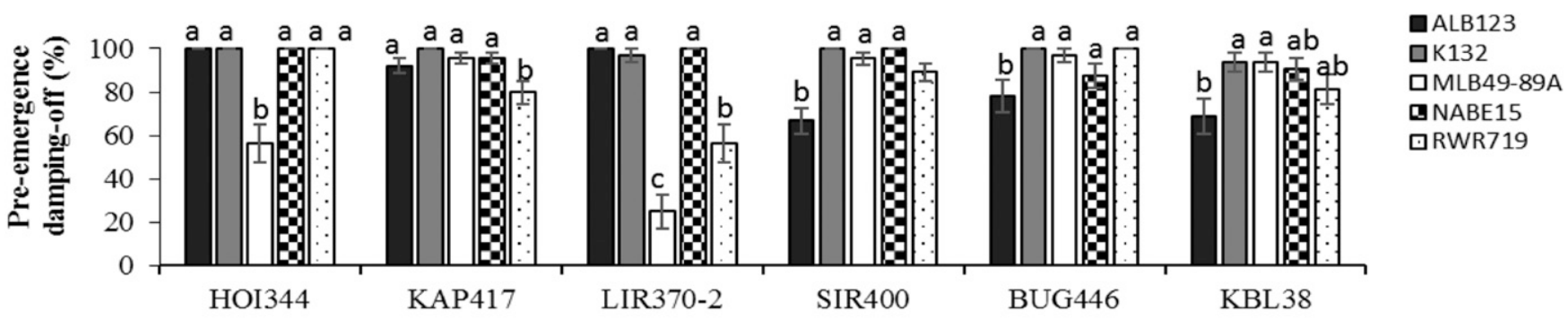

Isolates

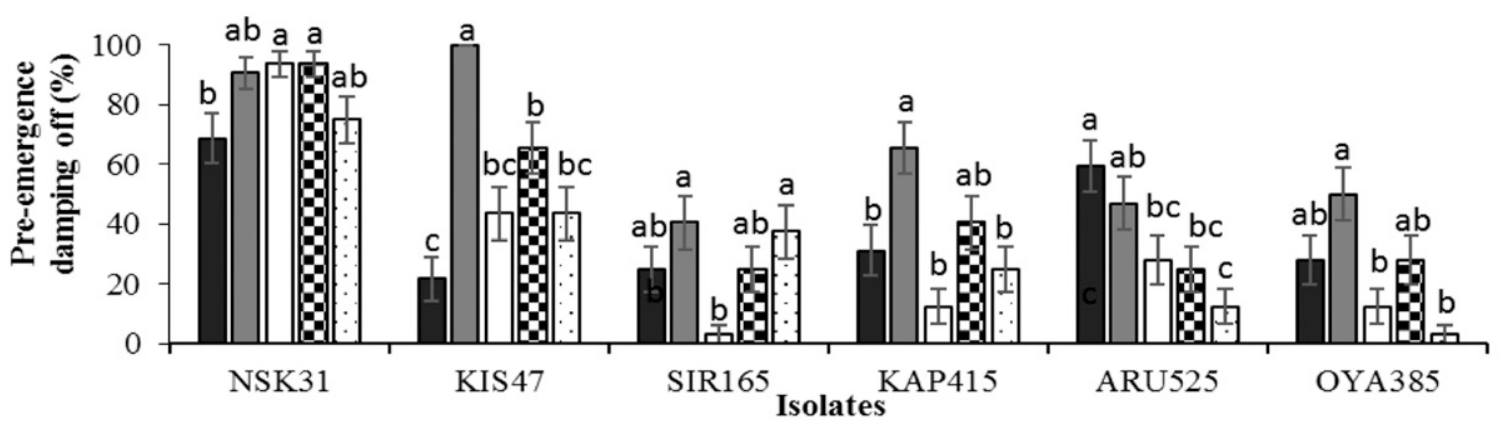

-ALB123

口K132

口MLB49-89A

QNABE15

口RWR719

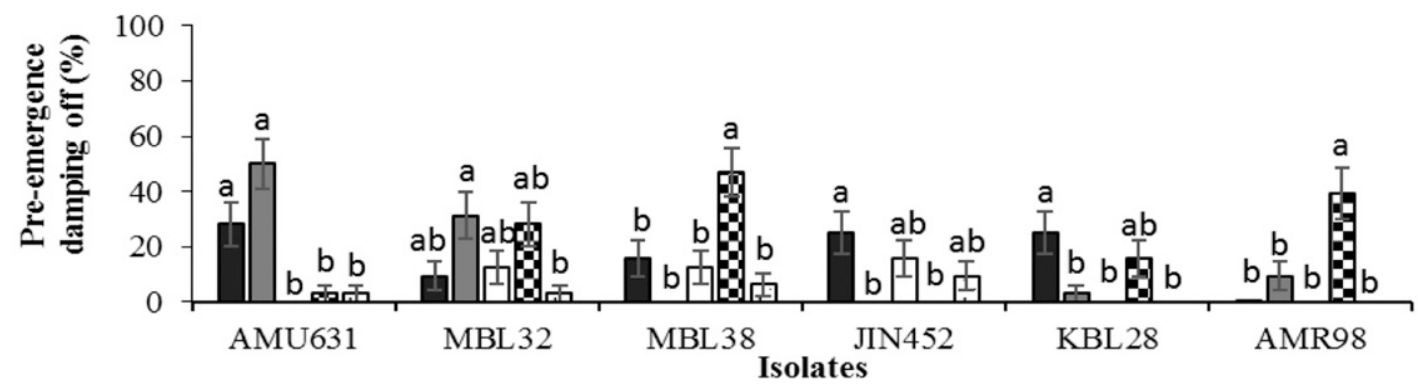

-ALB123

口K132

口MLB49-89A

DNABE15

DRWR719

Fig. 5. Preemergence damping-off caused by selected Sclerotium rolfsii isolates that varied in their effect on common bean test varieties ALB123, K132, MLB49-89A, NABE15, and RWR719. Different letters indicate differences at $P \leq 0.05$ (Tukey's studentized range test).

source of long-term survival structures in soils. Therefore, we consider that sclerotia density relates directly to the severity of Southern blight disease. However, further studies on the relationship between sclerotia number and Southern blight disease are required before sclerotia number can be considered as an indicator of isolate aggressiveness.

The Southern blight pathogen S. rolfsii on common bean in Uganda is morphologically and pathogenically diverse. This indicates the organism's adaptability to diverse agroecological conditions, a factor that has probably resulted in recent increases in the disease in all Ugandan bean-growing regions (Paparu et al. 2018). The threat of Southern blight to common bean was confirmed in our study, because all varieties tested were highly susceptible to $S$. rolfsii, including those known to be resistant to Fusarium root rot (MLB49-89A) and Pythium root rot (RWR719). Although our study provides information that was previously unavailable, additional work on $S$. rolfsii is required to include molecular evaluations of the isolates. This will give a fuller characterization of this organism and is the subject of ongoing work in our laboratory. Because the challenge to common bean plant breeders worldwide is to identify varieties that are tolerant or resistant to pathogens, a genotypic study would help to ensure that any variety developed for resistance to Southern blight is resistant to all known pathogen genotypes.

There is currently no common bean variety that is resistant to Southern blight in Uganda. Therefore, we advise farmers to manage Southern blight disease using effective and affordable methods such as removal and destruction of infected plants that act as sources of inoculum, treatment of seed with fungicides (e.g., Metalaxyl), inclusion of nonhost plants in crop rotations, and use of inorganic and organic soil fertility amendments.

\section{Literature Cited}

Adams, P. B., and Ayers, W. A. 1979. Ecology of Sclerotinia species. Phytopathology 69:896-899.

Akem, C. N., and Dashiell, K. E. 1991. First report of southern blight caused by Sclerotium rolfsii on soybean in Nigeria. Plant Dis. 75:537.

Aycock, R. 1966. Stem rot and other diseases caused by Sclerotium rolfsii or the status of Rolfs fungus after 70 years. N. C. Agric. Exp. Stn. Bull. No. 174.

Blum, L. E. B., and Rodriguez-Kabana, R. 2004. Effect of organic amendments on sclerotial germination, mycelial growth, and Sclerotium rolfsii induced diseases. Fitopatol. Bras. 29:66-74.

Bolton, M. D., Bart, P. H. J. T., and Nelson, B. D. 2006. Sclerotinia sclerotiorum (Lib.) de Bary: Biology and molecular traits of a cosmopolitan pathogen. Mol. Plant Pathol. 7:1-16.

Bonanomi, G., Antignani, V., Pane, C., and Scala, F. 2007. Suppression of soilborne fungal diseases with organic amendments. J. Plant Pathol. 89:311-324.

Bulluck, L. R., III, and Ristiano, J. B. 2002. Effect of synthetic and organic soil fertility amendments on southern blight, soil microbial communities, and yield of processing tomatoes. Phytopathology 92:181-189.

Chellemi, D. O. 2002. Nonchemical management of soil borne pests in fresh market vegetable production systems. Phytopathology 92:1367-1372.

Chiang, K. S., Liu, H. I., and Bock, C. H. 2017. A discussion on disease severity index values. Part I: Warning on inherent errors and suggestions to maximise accuracy. Ann. Appl. Biol. 171:139-154.

Domsch, K. H. 1980. Compendium of Soil Borne Fungi. Academic Press, London, U.K

Dukes, P. D., Fery, R. L., and Jones, A. L. 1983. Evaluating pepper, cow peas, sweet potato and tomatoes for resistance to southern blight incited by Sclerotium rolfsii Sacc. (Abstr.) Phytopathology 73:785-786. 
Farr, D. F., Bills, G. F., Chamuris, G. P., and Rossman, A. Y. 1989. Fungi on Plants and Plant Products in the United Sates. American Phytopathological Society, St. Paul, MN, U.S.A.

Fery, R. L., and Dukes, P. D., Sr. 2002. Southern blight (Sclerotium rolfsii Sacc.) of cowpea: Yield-loss estimates and source of resistance. Crop Prot. 21: 403-408.

Flores-Moctezuma, H. E., Montes-Belmont, R., Jiménez-Pérez, A., and NavaJuárez, R. 2006. Pathogenic diversity of Sclerotium rolfsii isolates from Mexico, and potential control of southern blight through solarization and organic amendments. Crop Prot. 25:195-201.

Fong, Y. K., Anuar, S., Lim, H. P., Tham, F. Y., and Sanderson, F. R. 2000. A modified filter paper technique for long-term preservation of some fungal cultures. Mycologist 14:127-130.

Franke, M., Brenneman, T. B., Stevenson, K. L., and Padgett, G. 1998. Sensitivity of isolates of Sclerotium rolfsii from peanut in Georgia from selected fungicides. Plant Dis. 82:578-583.

Garibaldi, A., Gilardi, G., and Gullino, M. L. 2006. First report of southern blight incited by Sclerotium rolfsii on potato (Solanum tuberosum) in Northern Italy. Plant Dis. 90:1114. doi: 10.1094/PD-90-1114C

Garibaldi, A., Gilardi, G., and Ortu, G. 2013. First report of southern blight caused by Sclerotium rolfsii on common bean (Phaseolus vulgaris L.) in Italy. Plant Dis. 97:1386.

Harlton, C. E., Lévesque, C. A., and Punja, Z. K. 1995. Genetic diversity in Sclerotium (Athelia) rolfsii and related species. Phytopathology 85:1269-1281.

Hernández-Morales, J., Ochoa-Martinéz, D. L., Ayala-Escoba, V., and OrtegaCosta, S. A. 2018. First report of southern blight caused by Sclerotium rolfsii on sesame in Mexico. J. Plant Pathol. 100:323.

Jebaraj, M. D., Aiyanathan, K. E. A., and Nakkeeran, S. 2017. Virulence and genetic diversity of Sclerotium rolfsii Sacc., infecting groundnut using nuclear (RAPD \& ISSR) markers. J. Environ. Biol. 38:147-159.

Kator, L., Kalu, O. J., and Umgbed, A. M. 2015. Evaluation of the disease-causing potential of Sclerotium rolfsii on tomato cultivars in bioassay (pathogenicity test). Ann. Biol. Res. 6:7-15.

Koné, D., Mohamed, D., Soro, S., Bolou Bi, B. A., and Kouadio, Y. J. 2010. First report of Southern blight of Okra (Abelmoschus esculentus) caused by Sclerotium rolfsii in Côte d'Ivoire. Plant Dis. 94:1379.

Le, C. N., Mendes, R., Kruijt, M., and Raaijmakers, J. M. 2012. Genetic and phenotypic diversity of Sclerotium rolfsii in groundnut fields in central Vietnam. Plant Dis. 96:389-397.

Lehner, M. S., Lima, R. C., Carneiro, J. E. S., Paula Júnior, T. J., Vieira, R. F., and Mizubuti, E. S. G. 2016. Similar aggressiveness of phenotypically and genotypically distinct isolates of Sclerotinia sclerotiorum. Plant Dis. 100: 360-366.

Lehner, M. S., Paula Júnior, T. J., Silva, R. A., Vieira, R. F., Carneiro, J. E. S., and Mizubuti, E. S. G. 2014. Sclerotia morphology traits and mycelial growth rate are not informative variables for population studies of Sclerotinia sclerotium. Trop. Plant Pathol. 39:471-477.

Li, Z., Zhang, M., Wang, Y., and Fernando, W. G. D. 2008. Mycelial compatibility group and pathogenicity variation of Sclerotinia sclerotiorum populations in sunflower from China, Canada and England. Plant Pathol. 7:131-139.
Mahadevakumar, S., Tejaswini, G. S., Janardhana, G. R., and Vandana, Y. 2015 First report of Sclerotium rolfsii causing southern blight and leaf spot of common bean (Phaseolus vulgaris) in India. Plant Dis. 99:1280.

Mahato, A., and Biswas, M. K. 2017. Cultural, morphological and pathogenic variability of different isolates of $S$. rolfsii obtained from rice-tomato-rice cropping system of undulating red and lateritic zone of West Bengal, India. Int. J. Curr. Microbiol. Appl. Sci. 6:1843-1851.

Mukankusi, M. C., Melis, R. J., Derera, J., Buruchara, R. A., and Mark, D. 2011. A screening technique for resistance to Fusarium root rot of common bean. Afr. J. Plant Sci. 5:152-161.

Mullen, J. 2001. Southern blight, southern stem blight, white mold. Plant Health Instruct. doi:10.1094/PHI-I-2001-0104-01

Narayan, C. P., Hwang, E., Nam, S., Lee, H., Lee, J., Yu, G., Kang, Y., Lee, K., Go, S., and Yang, J. 2017. Phylogenetic placement and morphological characterization of Sclerotium rolfsii (teleomorph: Athelia rolfsii) associated with blight disease of Ipomoea batatas in Korea. Microbiology 45:129-138.

Ongom, P. O., Nkalubo, S. T., Gibson, P. T., Mukankusi, C. M., and Rubaihayo, P. 2012. Inheritance of resistance to Fusarium root rot in three common bean genotypes. Electron. J. Plant Breed. 3:892-897.

Otsyula, R. M., Buruchara, R. A., Mahuku, G., and Rubaihayo, P. 2003. Inheritance and transfer of root rots (Pythium) resistance to bean genotypes. Afr. Crop Sci. Soc. 6:295-298.

Paparu, P., Acur, A., Kato, F., Acam, C., Nakibuule, J., Musoke, S., Nkalubo, S., and Mukankusi, C. 2018. Prevalence and incidence of four common bean root rots in Uganda. J. Exp. Agric. 54:888-900.

Prasad, S. I. 2012. Variability in Sclerotium rolfsii associated with collar rot of sunflower. Indian Phytopathol. 65:161-165.

Pratt, R. G., and Rowe, D. E. 2002. Enhanced resistance to Sclerotium rolfsii in populations of alfalfa selected for resistance to Sclerotinia trifolium. Phytopathology 92:204-209.

Punja, Z. K., Huang, J. S., and Jenkins, S. F. 1985. Relationship of mycelial growth and production of oxalic acid and cell wall degrading enzymes to virulence in Sclerotium Rolfsii. Can. J. Plant Pathol. 7:109-117.

Rolfs, P. H. 1892. Tomato blight-Some hints. Fla. Agric. Exp. Stn. Bull. 18.

Vleugels, T., Baert, J., and van Bockstaele, E. 2013. Morphological and pathogenic characterization of genetically diverse Sclerotinia isolates from European Red clover crops (Trifolium pratense L.). J. Phytopathol. 161: 254-262.

Woodward, J. E., Brenneman, T. B., Kemerait, R. C., Smith, N. B., Culbreath A. K., and Stevenson, K. L. 2008. Use of resistant cultivars and reduced fungicide programs to manage peanut diseases in irrigated and nonirrigated fields. Plant Dis. 92:896-902.

Wortmann, C. S., and Eledu, C. A. 1999. Uganda's Agro-Ecological Zones: A Guide for Planners and Policy Makers. Centro Internacional de Agricultura Tropical, Kampala, Uganda.

Xie, C., Huang, C. H., and Vallad, G. E. 2014. Mycelial compatibility and pathogenic diversity among Sclerotium rolfsii isolates in the Southern United States. Plant Dis. 98:1685-1694.

Yasmin, A., Mirza, M. S., and Aslam, M. 1984. Sclerotium rolfsii on maize. FAO Plant Prot. Bull. 32:147. 